\title{
Quantitative Assessment of the Synchronization of Cell Populations
}

\author{
By HELOISA B. M. WOLOSKER AND D. F. DE ALMEIDA \\ Laboratorio de Fisiologia Celular, Instituto de Biofísica da UFRJ, \\ Cidade Universitária, ZC-32, Rio de Janeiro, R.J., Brazil
}

(Received 15 June 1978)

\section{INTRODUCTION}

The inspection of growth curves does not constitute a precise and reliable method for determining the degree of synchronization of cell cultures. The need for quantification is felt particularly when one is trying to assess the efficacy of a synchronization technique (Helmstetter \& Cummings, 1964; Cummings, 1970; Wolosker \& Almeida, 1975, 1977) or when comparative studies are made of several techniques (Wolosker, 1976). Such need is certainly at the root of many attempts to provide an index for quantifying the degree of synchronization of cell populations (Mitchison, 1971). An objective appraisal of synchronization should take into account some parameters which characterize the population under study and distinguish it from the asynchronous one. Such factors were described by Scherbaum (1962) and duly considered in his derivation of a synchronization index (S.I.) which has been commonly applied (Scherbaum, 1964; Anagnostopoulos, 1975). However, the essential requirement that any S.I. should have a maximum value (generally 1 ) for the ideal synchronization and become zero for random exponential growth is not met by that index. We have re-examined Scherbaum's derivation and detected a small but significant inaccuracy which reveals why it fails to fulfil this basic requirement. We propose here the adoption of a new and more correct S.I.

\section{Derivation of the new S.I.}

The model growth curves used by Scherbaum for the derivation of the S.I. are of mixed character. While the random exponential curve is drawn to an arithmetical ordinate, variations in cell number for the synchronized multiplication are plotted to a logarithmic ordinate (Scherbaum, 1962, Fig. 1). Our derivation has been based on the model curves in Fig. 1, assuming a logarithmic scale on the ordinate. To allow for easy comparison, we have used the same designations as Scherbaum, S.I. being defined as the ratio $S_{1} / S_{2}$ between areas $\mathrm{N}_{0} \mathrm{AB}$ and $\mathrm{N}_{0} \mathrm{~N}^{\prime} \mathrm{B}$.

According to Scherbaum (1964),

$$
\text { S.I. }=1-\frac{t+g t(2-n)}{1 \cdot 12 g t}
$$

where $t$ is the period during which synchronous multiplication occurs, $g t$ is the generation time and

$$
n=1+\frac{\text { no. of cells dividing synchronously }}{\text { total no. of cells }}
$$

The derivation based on the model curves of Fig. 1 is as follows:

$$
\begin{gathered}
\mathrm{S}_{2}=\frac{g t\left(\ln 2 n_{0}-\ln n_{0}\right)}{2}=\frac{g t \ln 2}{2} \\
\mathrm{~S}_{1}=\mathrm{S}_{2}-\left(\mathrm{N}_{0} \mathrm{NA}+\mathrm{NN}^{\prime} \mathrm{CA}+\mathrm{ACB}\right)
\end{gathered}
$$




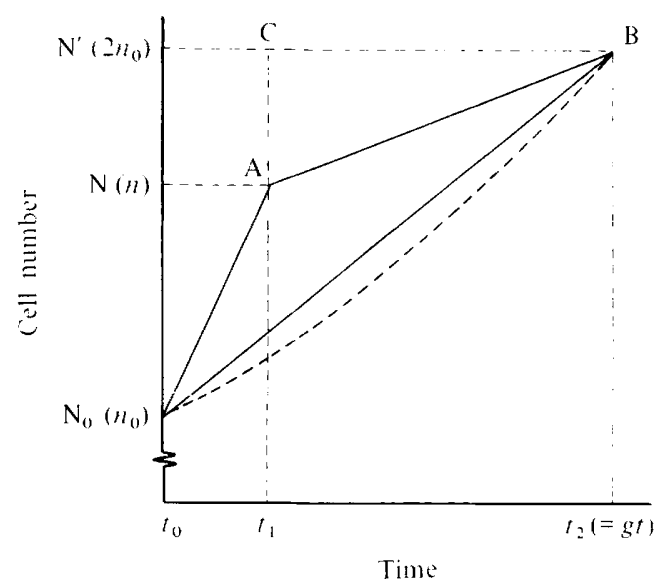

Fig. 1. Model growth curves, redrawn from Scherbaum (1962). Curve $\mathrm{N}_{0} \mathrm{~B}(-$ ) is the one used for the present derivation (logarithmic ordinates); curve $\mathrm{N}_{0} \mathrm{~B}(---)$ is drawn according to Scherbaum's original, which adopted linear ordinates.

$$
\begin{aligned}
& \mathrm{S}_{1}=\mathrm{S}_{2}-\frac{\left(\ln n-\ln n_{0}\right) t_{1}}{2}-\left(\ln 2 n_{0}-\ln n\right) t_{1}-\frac{\left(\ln 2 n_{0}-\ln n\right)\left(g t-t_{1}\right)}{2} \\
& =\frac{1}{2}\left(g t \ln 2-t_{1} \ln n+t_{1} \ln n_{0}-2 t_{1} \ln 2 n_{0}+2 t_{1} \ln n-g t \ln 2 n_{0}+t_{1} \ln 2 n_{0}\right. \\
& \left.+g t \ln n-t_{1} \ln n\right) \\
& =\frac{1}{2}\left(g t \ln 2+g t \ln n-g t \ln 2 n_{0}+t_{1} \ln n_{0}-t_{1} \ln 2 n_{0}\right) \\
& =\frac{1}{2}\left[g t \ln \left(2 n / 2 n_{0}\right)+t_{1} \ln \left(n_{0} / 2 n_{0}\right)\right] \\
& =\frac{1}{2}\left[g t \ln \left(n / n_{0}\right)-t_{1} \ln 2\right]
\end{aligned}
$$

Hence,

$$
\frac{\mathrm{S}_{1}}{\mathrm{~S}_{2}}=\text { S.I. }=\frac{g t \ln \left(n / n_{0}\right)-t_{1} \ln 2}{g t \ln 2}
$$

For random exponential growth, $n / n_{0}=2$ and $t_{1}=g t$, so

$$
\text { S.I. }=\frac{g t \ln 2-g t \ln 2}{g t \ln 2}=0
$$

For the ideal synchronization, $n / n_{0}=2$ and $t_{1}=0$, so

$$
\text { S.I. }=\frac{g t \ln 2-0}{g t \ln 2}=1
$$

Equation (3) can also be represented as

$$
\begin{aligned}
& \text { S.I. }=\frac{g t \ln \left(n / n_{0}\right)}{g t \ln 2}-\frac{t_{1} \ln 2}{g t \ln 2} \\
& \text { eading to } \\
& \text { S.I. }=\frac{1}{0 \cdot 693} \ln \left(n / n_{0}\right)-\frac{t_{1}}{g t} \\
& \text { or, for decimal logarithms, } \quad \text { S.I. }=\frac{1}{0 \cdot 301} \log _{10}\left(n / n_{0}\right)-\frac{t_{1}}{g t} \\
& \text { In addition, when } n=2 n_{0} \text {, S.I. }=1-\frac{t_{1}}{g t}
\end{aligned}
$$

This new S.I. gives results which are 8 to $10 \%$ lower than values obtained with the original S.I. (Scherbaum, 1962), particularly when the index is higher than $0 \cdot 50$. More 
importantly, the new index constitutes a fully correct representation of the underlying theory.

This work was supported by grants from ${ }^{-C E P G / U F R J, ~ C N P q ~(p r o j e c t ~ S I P / 04 / 051) ~ a n d ~}$ FINEP (FNDCT-375/CT). H.B.M.W. holds a scholarship from CAPES.

\section{REFERENCES}

Anagnostopoulos, G. D. (1975). Defining synchrony of cell cultures. Archives of Microbiology 104, 95-96.

Cummings, D. J. (1970). Synchronization of E. coli $\mathrm{K} 12$ by membrane selection. Biochemical and Biophysical Research Communication 41, 471-476.

Helmstetter, C. E. \& Cummings, D. J. (1964). An improved method for the selection of bacterial cells at division. Biochimica et biophysica acta $\mathbf{8 2}$, 608-610.

Mitchison, J. M. (1971). The Biology of the Cell Cycle, pp. 56-57. London: Cambridge University Press.

Scherbaum, O. H. (1962). A comparison of synchronized cell division in protozoa. Journal of Protozoology 9, 61-64.
Scherbaum, O. H. (1964). Comparison of synchronous and synchronized cell division. Experimental Cell Research 33, 89-98.

Wolosker, H. B. M. (1976). Estudo de algumas propriedades associadas ao processo de sincronização de Escherichia coli $\mathrm{K} 12$. M.Sc. thesis, Federal University of Rio de Janeiro, Brazil.

Wolosker, H. B. M. \& Almeida, D. F. de (1975). Two-step doubling of synchronous cultures of Escherichia coli k12. Journal of General Microbiology 88, 381-383.

Wolosker, H. B. M. \& Almeida, D. F. DE (1977). Timing of cold-sensitive stages in the cell division cycle of Escherichia coli $\mathrm{k} 12$. Journal of General Microbiology 99, 99-105. 